Sheri L. Spunt, Victor M. Santana, Richard J. Gilbertson, St Jude Children's Research Hospital; Sheri L. Spunt, Victor M. Santana, University of Tennessee Health Science Center, Memphis, TN; Stephan A. Grupp, Children's Hospital of Philadelphia, Philadelphia Joseph P. Boni, Pfizer, Collegeville, PA; Terry A. Vik, Riley Hospital for Children, Indianapolis, IN; David J. Greenblatt, Tufts University School of Medicine, Boston; Jill Clancy, Revathi Ananthakrishnan, inVentiv Clinical Solutions; and Anna Berkenblit, Mizue Krygowski, Pfizer, Cambridge, MA.

Submitted October 27, 2010; accepted March 30, 2011; published online ahead of print at www.jco.org on June 20, 2011 .

Supported in part by Wyeth Research (which was acquired by Pfizer in October 2009) through grants to S.L.S., S.A.G., T.A.V., V.M.S., and R.J.G.; by Solid Tumor Program Project Grant No. CA23099 to S.L.S., V.M.S., and R.J.G.; by Cancer Center Support CORE Grant No. P30 CA 21765 from the National Cancer Institute to S.L.S., V.M.S., and R.J.G.; and by funding from the American Lebanese Syrian Associated Charities to S.L.S., V.M.S., and R.J.G. No author received an honorarium or other form of financial support related to the development of this manuscript.

Presented in part at the Pediatric Academic Societies Annual Meeting, May 5-8, 2007, Toronto, Ontario,

Canada.

Authors' disclosures of potential conflicts of interest and author contributions are found at the end of this article.

Clinical Trials repository link available on JCO.org.

Corresponding author: Sheri L. Spunt, MD, Department of Oncology, St Jude Children's Research Hospital, 262 Danny Thomas Place, S-6011, Memphis, TN 38105-3678; e-mail: sheri.spunt@stjude.org.

(C) 2011 by American Society of Clinical Oncology

0732-183X/11/2921-2933/\$20.00

DOI: $10.1200 / J C O .2010 .33 .4649$

\title{
Phase I Study of Temsirolimus in Pediatric Patients With Recurrent/Refractory Solid Tumors
}

Sheri L. Spunt, Stephan A. Grupp, Terry A. Vik, Victor M. Santana, David J. Greenblatt, Jill Clancy, Anna Berkenblit, Mizue Krygowski, Revathi Ananthakrishnan, Joseph P. Boni, and Richard J. Gilbertson

$$
\begin{array}{llllllll}
\text { A } & \text { B } & \text { S } & \text { T } & \text { R } & \text { A } & \text { C } & \text { T }
\end{array}
$$

\section{Purpose}

To determine dose-limiting toxicities, maximum-tolerated dose (MTD), pharmacokinetics, and pharmacodynamics of weekly intravenous temsirolimus, a mammalian target of rapamycin (mTOR) signaling pathway inhibitor, in pediatric patients with recurrent or refractory solid tumors.

\section{Patients and Methods}

Cohorts of three to six patients 1 to 21 years of age with recurrent or refractory solid tumors were treated with a 1-hour intravenous infusion of temsirolimus weekly for 3 weeks per course at one of four dose levels: $10,25,75$, or $150 \mathrm{mg} / \mathrm{m}^{2}$. During the first two courses, pharmacokinetic and pharmacodynamic evaluations (phosphorylation of S6, AKT, and 4EBP1 in peripheral-blood mononuclear cells) were performed.

\section{Results}

Dose-limiting toxicity (grade 3 anorexia) occurred in one of 18 evaluable patients at the $150 \mathrm{mg} / \mathrm{m}^{2}$ level, which was determined to be tolerable, and an MTD was not identified. In 13 patients evaluable for response after two courses of therapy, one had complete response (CR; neuroblastoma) and five had stable disease (SD). Four patients (three SDs + one CR) remained on treatment for more than 4 months. The sum of temsirolimus and sirolimus areas under the concentrationtime curve was comparable to values in adults. AKT and 4EBP1 phosphorylation were inhibited at all dose levels, particularly after two courses.

\section{Conclusion}

Weekly intravenous temsirolimus is well tolerated in children with recurrent solid tumors, demonstrates antitumor activity, has pharmacokinetics similar to those in adults, and inhibits the mTOR signaling pathway in peripheral-blood mononuclear cells. Further studies are needed to define the optimal dose for use in combination with other antineoplastic agents in pediatric patients.

\section{J Clin Oncol 29:2933-2940. (C) 2011 by American Society of Clinical Oncology}

\section{INTRODUCTION}

Many human cancers are characterized by activation of the mammalian target of rapamycin (mTOR) protein, a serine threonine kinase involved in cell cycle regulation, angiogenesis, and apoptosis. ${ }^{1-3}$ The mTOR protein participates in two multiprotein complexes: mTOR complex 1 (mTORC1), which regulates growth via translational regulator p70S6 kinase and initiation factor $4 \mathrm{E}-\mathrm{BP} 1,4,5$ and $\mathrm{mTOR}$ complex 2 (mTORC2), which influences cell survival via phosphorylation of $\mathrm{AKT}^{\mathrm{Ser} 473}{ }^{6}$

Temsirolimus is a potent and highly specific inhibitor of mTOR, as evidenced by its inhibition of phosphorylation of p70S6 kinase and 4E-BP1 in both in vitro and in vivo tumor model systems. ${ }^{7,8}$ It has antitumor activity in many human cancers, including various carcinomas (renal cell, ${ }^{9}$ breast, ${ }^{10}$ lung, ${ }^{11}$ pancreatic, ${ }^{12}$ prostate, ${ }^{13}$ and colon ${ }^{7}$ ) and hematologic malignancies ${ }^{14}$ (mantle-cell lymphoma, ${ }^{15}$ acute lymphocytic leukemia, ${ }^{16}$ and multiple myeloma ${ }^{17}$ ). Temsirolimus was the first mTOR inhibitor approved by the US Food and Drug Administration for use in oncology, where it is approved for the treatment of advanced renal cell carcinoma. ${ }^{18}$ In adults, temsirolimus is well tolerated at intravenous doses ranging from 7.5 to $220 \mathrm{mg} / \mathrm{m}^{2}$ weekly, ${ }^{19}$ with rash and stomatitis being the most common associated toxicities. Pharmacokinetic analyses demonstrated that levels of temsirolimus achieved in the blood exceeded the concentrations required for inhibition of $\mathrm{mTOR}$ and tumor cell growth in vitro. Inhibition of mTOR activity has also been demonstrated in adults treated with temsirolimus by measurement of pS6 kinase in peripheral blood mononuclear cells. ${ }^{20}$ These observations led to dose selection for further 
studies in adults based not on the standard definition for maximumtolerated dose (MTD), but on the dose required for biologic activity.

Several mTOR inhibitors have demonstrated significant antitumor activity in both in vivo and in vitro pediatric solid tumor models, including rhabdomyosarcoma, gliomas, and neuroblastoma, ${ }^{7,21-25}$ but no clinical trials of temsirolimus in pediatric patients have been reported. This phase I/II study was conducted in two parts and was designed to evaluate the safety and activity of intravenous temsirolimus in children with cancer. The phase I component was an ascending-dose safety study in pediatric patients with advanced solid tumors, and the results are reported herein. The phase II component was a preliminary evaluation of antitumor activity in pediatric patients with neuroblastoma, rhabdomyosarcoma, and high-grade glioma, and results are reported separately. ${ }^{26}$

\section{PATIENTS AND METHODS}

\section{Patients}

Eligible patients were male or female patients 1 to 21 years of age. Eligibility and exclusion criteria are summarized in Table 1. Patients or their legal guardians provided written informed consent before study participation.

\section{Study Design}

The institutional review boards of the three participating institutions approved the study protocol. This study was performed in accordance with the Declaration of Helsinki and Good Clinical Practice Guidelines.

Temsirolimus was supplied by Wyeth Pharmaceuticals (Philadelphia, PA) and was administered intravenously over 60 minutes once weekly (one course $=21$ days). Premedication with intravenous diphenhydramine $1 \mathrm{mg} / \mathrm{kg}$ was given 30 minutes before the start of each temsirolimus infusion. The starting temsirolimus dose was $10 \mathrm{mg} / \mathrm{m}^{2}$, with escalation planned to 25 , 75 , and $150 \mathrm{mg} / \mathrm{m}^{2}$ based on experience in adult subjects receiving doses ranging from 7.5 to $220 \mathrm{mg} / \mathrm{m}^{2}{ }^{19}$ A minimum of three patients assessable for toxicity were to be treated at each dose level. If a dose-limiting toxicity (DLT) was not observed among the first three assessable patients treated at aiven dose level, then the dose was escalated. If one of three patients experienced a DLT, then an additional three patients were treated at that dose level. In the absence of further DLTs, the dose was escalated. The MTD was defined as the dose level immediately below that at which two more patients experienced DLTs during the first course of treatment. Six assessable patients were to be treated at the MTD. There was no intra-patient dose escalation. Patients who experienced a DLT could continue treatment at the next lower dose level after resolution of toxicity; a further DLT prompted removal from the study. Those without DLTs could continue therapy until disease progression occurred.

Toxicity was graded according to the National Cancer Institute Common Terminology Criteria for Adverse Events, version 3.0. Only toxicity during the first course of treatment was used to determine the MTD. Grade 4 thrombocytopenia or neutropenia of more than 7 days in duration was classified as a hematologic DLT. Nonhematologic DLTs included all grade 3 or 4 nonhematologic toxicities, except for asymptomatic grade 3 electrolytes, grade 3 nausea/vomiting/diarrhea responsive to medical therapy, grade 3 AST or ALT with recovery to grade 1 before the next course, and serum triglycerides less than $1,500 \mathrm{mg} / \mathrm{dL}$ with recovery to baseline before the next course. Delay in treatment for more than 2 weeks because of an unresolved temsirolimusrelated toxicity was also considered dose limiting.

Pretreatment evaluations included a medical history, physical examination, performance status assessment, echocardiogram, complete blood count with differential (CBC), coagulation profile, serum electrolytes, renal and liver function tests, cholesterol, low-density lipoprotein, high-density lipoprotein, triglycerides, and urinalysis. During treatment, patients were seen weekly for a physical examination, performance status assessment, and CBC; serum chemistries and liver function tests were obtained every 2 weeks. The protocol cautioned against using CYP3A4 inducers or inhibitors and drugs that are CYP2D6 substrates due to potential pharmacokinetic interactions.

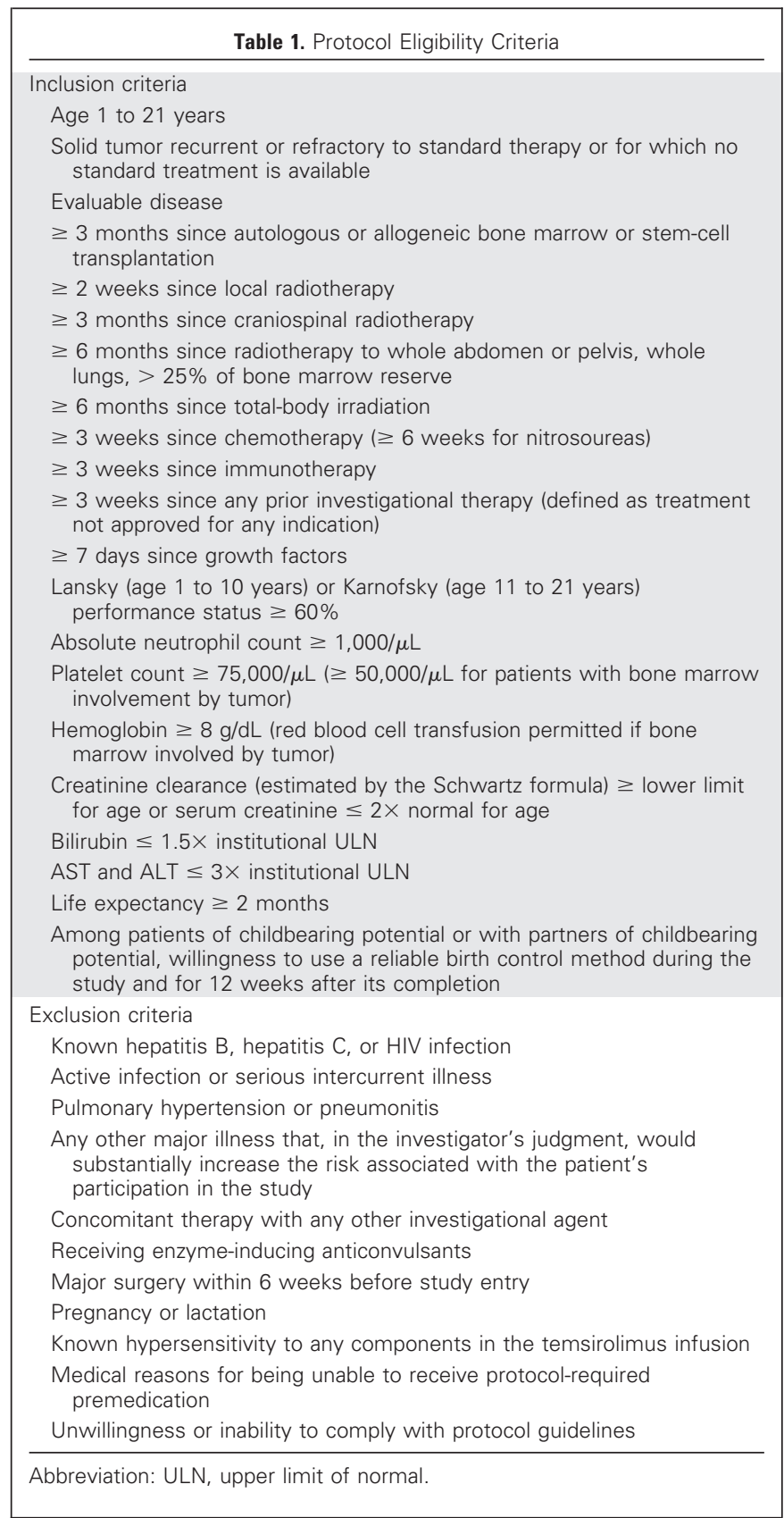

Disease evaluations were performed at baseline and after every two courses thereafter. Tumor response was evaluated using the Response Evaluation Criteria in Solid Tumors (RECIST), ${ }^{27}$ excepting patients with neuroblastoma who were evaluated by the International Neuroblastoma Response Criteria. ${ }^{28}$ To be assigned a status of complete response, very good partial response, or partial response, the response must have been confirmed by repeated evaluation $\geq 4$ weeks after the initial assessment.

\section{Pharmacokinetic Studies}

Pharmacokinetic studies to measure temsirolimus and sirolimus levels were required during the first two courses. Whole-blood samples $(2 \mathrm{~mL})$ were collected in an EDTA-treated tube before temsirolimus administration and at $1,2,6,24$, and 168 hours after administration. During course 2, samples were also obtained at 72 and 96 hours after drug administration. Samples were mixed, transferred into a separate polypropylene tube, and stored at $-70^{\circ} \mathrm{C}$ until shipped for processing. Temsirolimus and sirolimus were simultaneously 
measured using a validated liquid chromatography/tandem mass spectrometry method with an internal standard. Mean intra-day and inter-day variability of temsirolimus and sirolimus quality control samples was $15.1 \%$ or less in both the low-range and high-range assays.

Pharmacokinetic parameters, including peak observed concentration $\left(\mathrm{C}_{\max }\right)$, time to $\mathrm{C}_{\max }\left(\mathrm{t}_{\max }\right)$, area under the concentration-time curve to the last measurable time point $\left(\mathrm{AUC}_{\mathrm{T}}\right)$ and to infinity (AUC), half-life $(\mathrm{t})$, clearance $(\mathrm{CL})$, steady-state volume of distribution $\left(\mathrm{V}_{\mathrm{dss}}\right)$, sum of temsirolimus plus sirolimus AUCs $\left(\mathrm{AUC}_{\text {sum }}\right)$, and ratio of sirolimus-to-temsirolimus AUCs $\left(\mathrm{AUC}_{\text {ratio }}\right)$, were derived from the concentration-time profiles using a noncompartmental analysis method. For sirolimus, values of CL and $\mathrm{V}_{\mathrm{dss}}$ were reported as apparent measures and were normalized by the unknown fraction of dose metabolized $\left(f_{m}\right)$.

\section{Pharmacodynamic Studies}

Required pharmacodynamic studies were performed using wholeblood $(5 \mathrm{~mL})$ specimens obtained before administration of temsirolimus and at 1, 2, 8, 24, and 168 hours (course 1) and at 1, 24, 72, 96, 168 hours, and days 16 through 21 (course 2) after treatment. CPT tubes (BectonDickinson, Franklin Lakes, NJ) were used for one-step blood collection and separation of peripheral-blood mononuclear cells (PBMCs). Total protein was then extracted from each PBMC pellet and stored at $-80^{\circ} \mathrm{C}$ until analyzed. Levels of $\mathrm{pS}^{\mathrm{Ser} 235 / 236}, \mathrm{pAKT}^{\mathrm{Ser} 473}$ and $\mathrm{p} 4 \mathrm{EBP} 1^{\mathrm{Thr37/46}}$ expression in PBMC isolates at each time point were determined using standard Western blotting techniques. ${ }^{29}$ The levels of detected phosphoproteins were recorded relative to the corresponding total protein concentration in each sample. Actin was used as a loading and transfer control in each Western blot analysis.

\section{RESULTS}

Nineteen patients were enrolled onto the study. Table 2 shows the characteristics of these patients, who were treated on four dose levels: $10 \mathrm{mg} / \mathrm{m}^{2}(\mathrm{n}=4), 25 \mathrm{mg} / \mathrm{m}^{2}(\mathrm{n}=5), 75 \mathrm{mg} / \mathrm{m}^{2}(\mathrm{n}=3)$, and $150 \mathrm{mg} / \mathrm{m}^{2}(\mathrm{n}=7)$. At all dose levels, the median number of temsirolimus doses per patient was six (range, two to 79 doses). The median relative dose-intensity $\left(\mathrm{mg} / \mathrm{m}^{2} / \mathrm{wk}\right.$ administered divided by $\mathrm{mg} / \mathrm{m}^{2} /$ wk expected) ranged from 0.96 to 1.00 for each of the four dose levels studied.

\section{Regimen Toxicity}

Table 3 shows the DLTs observed at each dose level during the first course of treatment. Eighteen of the 19 patients received the first three doses of temsirolimus and were therefore fully assessable for DLTs. The remaining patient (at $25 \mathrm{mg} / \mathrm{m}^{2}$ ) discontinued therapy on day 15 of course 1 before the third dose of temsirolimus as a result of disease progression. One protocol-defined DLT was observed in a patient treated at the $150 \mathrm{mg} / \mathrm{m}^{2}$ dose level: grade 3 anorexia. A grade 3 prolonged activated partial thromboplastin time was also observed. However, this patient had a preexisting grade 3 prolonged activated partial thromboplastin of uncertain etiology at study entry that was asymptomatic and not associated with any clinical consequences; therefore, it was ultimately judged not to meet the criteria for a DLT. Thus the $150-\mathrm{mg} / \mathrm{m}^{2}$ dose level was determined to be tolerable.

At least one toxicity potentially attributable to temsirolimus occurred in each of the patients enrolled on the study at some time during their treatment (Table 4). The most common treatmentrelated adverse events were anemia, leukopenia, and thrombocytopenia (10 patients, 53\% each); neutropenia (nine patients, $47 \%$ ); and anorexia and hyperlipidemia (eight patients, $42 \%$ each). Nine patients $(47 \%)$, four of whom were in the $150 \mathrm{mg} / \mathrm{m}^{2}$ cohort,

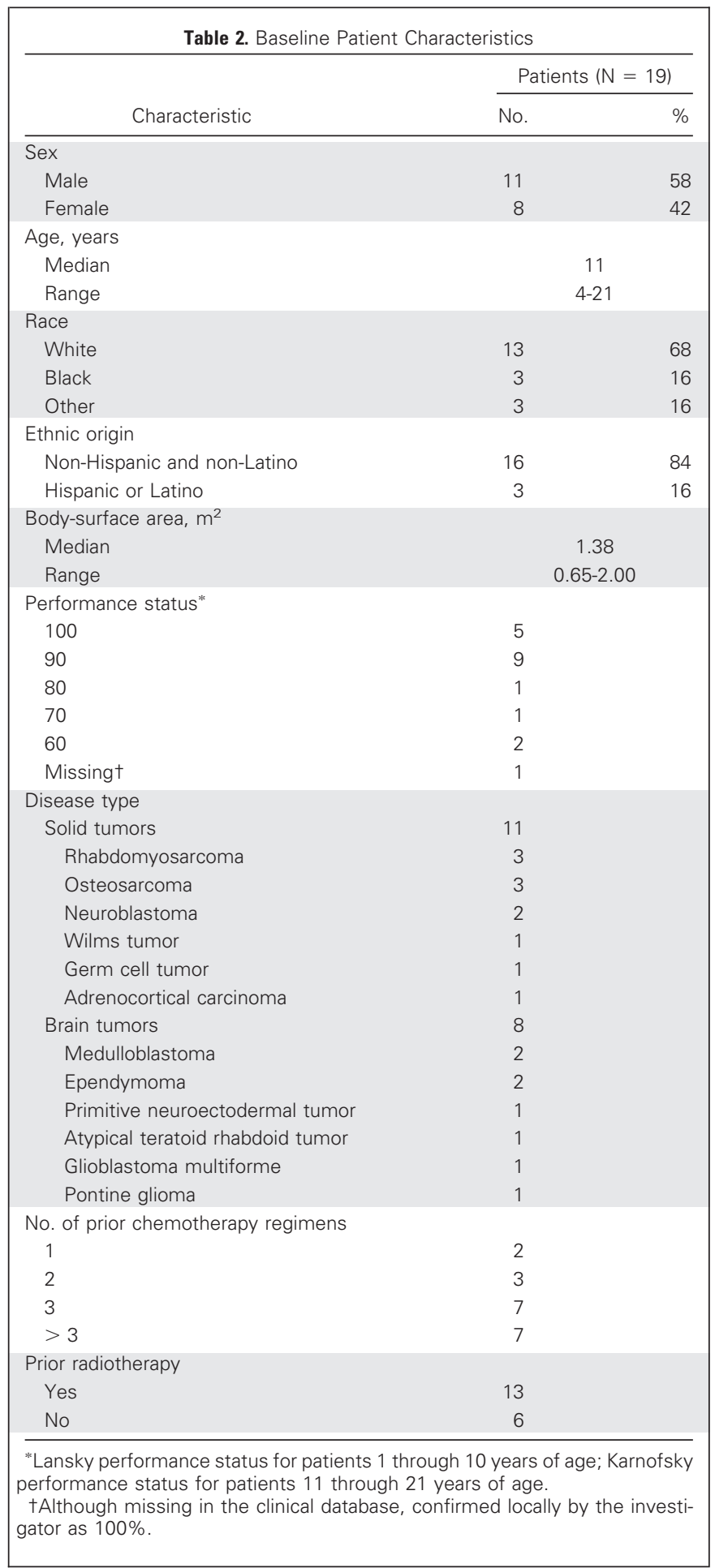

experienced grade 3 or 4 treatment-related adverse events. Grade 3 and 4 toxicities potentially related to temsirolimus therapy were uncommon after course 1 . Among 16 patients who began course 2, no patient discontinued temsirolimus therapy as a result of intolerable toxicity. One patient in the $25-\mathrm{mg} / \mathrm{m}^{2}$ cohort had one dose reduction, and one patient in the $150-\mathrm{mg} / \mathrm{m}^{2}$ cohort required one dose reduction. 


\begin{tabular}{ccccc}
\hline & & \multicolumn{2}{c}{ Table 3. Dose-Escalation Results and Experience } \\
\hline Cohort & Dose $\left(\mathrm{mg} / \mathrm{m}^{2}\right)$ & No. of Patients & No. of Patients With DLTs (course 1) & Other Clinically Significant Safety Considerations \\
\hline 1 & 10 & 4 & 0 & - \\
2 & 25 & 5 & 0 & - \\
3 & 75 & 3 & 0 & 1 patient with grade 3 aPTT prolonged; 1 patient with grade 4 \\
4 & 150 & 7 & thrombocytopenia lasting 6 days; 1 patient with grade 2 \\
& & & & vomiting lasting 3 days \\
\hline
\end{tabular}

Abbreviations: aPTT, activated partial thromboplastin time; DLT, dose-limiting toxicity.

\section{Tumor Responses}

Thirteen of the 19 patients completed at least two courses of therapy and were evaluable for tumor response: complete response $(\mathrm{CR} ; \mathrm{n}=1)$, stable disease (SD; $\mathrm{n}=5)$, and progressive disease $(\mathrm{n}=7)$. The CR occurred in a child with multiply recurrent neuroblastoma involving the left axilla and xiphoid process (both sites identified by metaiodobenzylguanidine scan) who received treatment at the first dose level, $10 \mathrm{mg} / \mathrm{m}^{2}$. Preceding therapy included all known active agents in neuroblastoma, two autologous stem-cell transplants, and other investigational agents. A CR was noted after course 4 and was maintained for four additional courses, at which time new distant metastases were identified (total time on therapy, 253 days). Three patients with SD remained on treatment for more than 4 months: ependymoma (569 days on therapy), germ cell tumor (177 days on therapy), and adrenocortical carcinoma (133 days on therapy).

Of the six patients who did not complete two courses of therapy, two had SD, two had progressive disease, and two were not evaluated for response. One patient discontinued owing to an adverse event (grade 3 thrombocytopenia), one because of symp- tomatic deterioration, two to pursue other therapy, and two because of disease progression.

\section{Pharmacokinetics}

Pharmacokinetic data were available from all 19 patients (Table 5). Drug concentrations seemed to decline in a polyexponential fashion. $\mathrm{C}_{\max }, \mathrm{AUC}, \mathrm{CL}$, and $\mathrm{AUC}_{\text {sum }}$ increased with dose. In course 1 after the first dose, median $\mathrm{C}_{\text {max }}$ ranged from $316 \mathrm{ng} / \mathrm{mL}\left(10 \mathrm{mg} / \mathrm{m}^{2}\right.$ dose) to $2,800 \mathrm{ng} / \mathrm{mL}$ ( $150 \mathrm{mg} / \mathrm{m}^{2}$ dose $)$ and was observed at the end of the infusion. One patient who received the $150-\mathrm{mg} / \mathrm{m}^{2}$ dose exhibited an unusually high $\mathrm{C}_{\max }$ value $(50,400 \mathrm{ng} / \mathrm{mL})$ and experienced grade 4 thrombocytopenia. This measure was limited to parent drug only, did not reflect in commensurately high values at later time points, and did not seem to explain the platelet attenuation observed in this patient. Otherwise, variabilities in $\mathrm{C}_{\max }$ were moderate (coefficient of variation $\leq 43 \%$ for all treatment groups) and no other correlations were noted between pharmacokinetic parameters and toxicity. The AUC and CL varied more than $\mathrm{C}_{\max }$, presumably because of the paucity of measures between the 96- and 168-hour time

\begin{tabular}{|c|c|c|c|c|c|c|c|c|c|c|c|c|c|c|c|c|c|c|c|c|}
\hline \multirow[b]{4}{*}{ Adverse Event† } & \multicolumn{20}{|c|}{ Temsirolimus Dose $\left(\mathrm{mg} / \mathrm{m}^{2}\right)$} \\
\hline & \multicolumn{4}{|c|}{$10(n=4)$} & \multicolumn{4}{|c|}{$25(n=5)$} & \multicolumn{4}{|c|}{$75(n=3)$} & \multicolumn{4}{|c|}{$150(n=7)$} & \multicolumn{4}{|c|}{ All Patients $(n=19)$} \\
\hline & \multicolumn{2}{|c|}{ All Grades } & \multicolumn{2}{|c|}{ Grade 3-4 } & \multicolumn{2}{|c|}{ All Grades } & \multicolumn{2}{|c|}{ Grade 3-4 } & \multicolumn{2}{|c|}{ All Grades } & \multicolumn{2}{|c|}{ Grade 3-4 } & \multicolumn{2}{|c|}{ All Grades } & \multicolumn{2}{|c|}{ Grade 3-4 } & \multicolumn{2}{|c|}{ All Grades } & \multicolumn{2}{|c|}{ Grade 3-4 } \\
\hline & No. & $\%$ & No. & $\%$ & No. & $\%$ & No. & $\%$ & No. & $\%$ & No. & $\%$ & No. & $\%$ & No. & $\%$ & No. & $\%$ & No. & $\%$ \\
\hline Any & 4 & 100 & 1 & 25 & 5 & 100 & 2 & 40 & 3 & 100 & 2 & 67 & 7 & 100 & 4 & 57 & 19 & 100 & 9 & 47 \\
\hline Anemia & 2 & 50 & 1 & 25 & 0 & 0 & 0 & 0 & 2 & 67 & 0 & 0 & 6 & 86 & 1 & 14 & 10 & 53 & 2 & 11 \\
\hline Leukopenia & 1 & 25 & 0 & 0 & 1 & 20 & 1 & 20 & 3 & 100 & 1 & 33 & 5 & 71 & 1 & 14 & 10 & 53 & 3 & 16 \\
\hline Thrombocytopenia & 1 & 25 & 0 & 0 & 2 & 40 & 0 & 0 & 3 & 100 & 0 & 0 & 4 & 57 & 2 & 29 & 10 & 53 & 2 & 11 \\
\hline Neutropenia & 0 & 0 & 0 & 0 & 2 & 40 & 2 & 40 & 3 & 100 & 2 & 67 & 4 & 57 & 1 & 14 & 9 & 47 & 5 & 26 \\
\hline Hyperlipidemia & 1 & 25 & 0 & 0 & 3 & 60 & 0 & 0 & 2 & 67 & 0 & 0 & 2 & 29 & 0 & 0 & 8 & 42 & 0 & 0 \\
\hline Anorexia & 1 & 25 & 0 & 0 & 0 & 0 & 0 & 0 & 1 & 33 & 0 & 0 & 6 & 86 & 1 & 14 & 8 & 42 & 1 & 5 \\
\hline Hypercholesterolemia & 0 & 0 & 0 & 0 & 2 & 40 & 0 & 0 & 1 & 33 & 0 & 0 & 4 & 57 & 0 & 0 & 7 & 37 & 0 & 0 \\
\hline Hypokalemia & 1 & 25 & 0 & 0 & 1 & 20 & 0 & 0 & 2 & 67 & 0 & 0 & 3 & 43 & 0 & 0 & 7 & 37 & 0 & 0 \\
\hline Hypoproteinemia & 2 & 50 & 0 & 0 & 0 & 0 & 0 & 0 & 1 & 33 & 0 & 0 & 4 & 57 & 0 & 0 & 7 & 37 & 0 & 0 \\
\hline AST increased & 2 & 50 & 0 & 0 & 2 & 40 & 0 & 0 & 1 & 33 & 0 & 0 & 2 & 29 & 0 & 0 & 7 & 37 & 0 & 0 \\
\hline Vomiting & 1 & 25 & 0 & 0 & 1 & 20 & 0 & 0 & 1 & 33 & 0 & 0 & 4 & 57 & 0 & 0 & 7 & 37 & 0 & 0 \\
\hline Mucositis & 1 & 25 & 0 & 0 & 1 & 20 & 0 & 0 & 1 & 33 & 0 & 0 & 3 & 43 & 0 & 0 & 6 & 32 & 0 & 0 \\
\hline Rash & 0 & 0 & 0 & 0 & 1 & 20 & 0 & 0 & 1 & 33 & 0 & 0 & 4 & 57 & 0 & 0 & 6 & 32 & 0 & 0 \\
\hline Hyperglycemia & 0 & 0 & 0 & 0 & 3 & 60 & 0 & 0 & 0 & 0 & 0 & 0 & 2 & 29 & 0 & 0 & 5 & 26 & 0 & 0 \\
\hline Diarrhea & 1 & 25 & 0 & 0 & 1 & 20 & 0 & 0 & 1 & 33 & 0 & 0 & 2 & 29 & 0 & 0 & 5 & 26 & 0 & 0 \\
\hline Nausea & 0 & 0 & 0 & 0 & 1 & 20 & 0 & 0 & 2 & 67 & 0 & 0 & 2 & 29 & 0 & 0 & 5 & 26 & 0 & 0 \\
\hline Asthenia & 0 & 0 & 0 & 0 & 1 & 20 & 0 & 0 & 0 & 0 & 0 & 0 & 4 & 57 & 0 & 0 & 5 & 26 & 0 & 0 \\
\hline
\end{tabular}




\begin{tabular}{|c|c|c|c|c|c|c|c|c|}
\hline \multirow[b]{3}{*}{ Agent } & \multicolumn{8}{|c|}{ Dose Level $\left(\mathrm{mg} / \mathrm{m}^{2}\right)$} \\
\hline & \multicolumn{2}{|c|}{$10(n=4)$} & \multicolumn{2}{|c|}{$25(n=5)$} & \multicolumn{2}{|c|}{$75(n=3)$} & \multicolumn{2}{|c|}{$150(n=7)$} \\
\hline & Median & Range & Median & Range & Median & Range & Median & Range \\
\hline \multicolumn{9}{|l|}{ Temsirolimus } \\
\hline $\mathrm{C}_{\max }, \mathrm{ng} / \mathrm{mL}$ & 316 & $190-407$ & 448 & $353-726$ & 442 & $369-630$ & 2,800 & $1,200-50,400$ \\
\hline$t_{\text {max }} h$ & 1.0 & $0.9-1.3$ & 1.1 & $1.0-1.2$ & 1.4 & $1.08-1.5$ & 1.0 & $1.0-1.6$ \\
\hline $\mathrm{t}, \mathrm{h}$ & 10.8 & $9.9-11.1$ & 16.2 & $9.9-23.1$ & 24 & $24-24$ & 21.4 & $4.8-29.5$ \\
\hline $\mathrm{A} \cup \mathrm{C}, \mathrm{h} \cdot \mathrm{ng} / \mathrm{mL}$ & 1,670 & $1,290-3,360$ & 3,570 & $2,070-9,330$ & 2,810 & $2,810-2,810$ & 5,190 & $3,220-38,300$ \\
\hline $\mathrm{CL}, \mathrm{L} / \mathrm{h}$ & 5.8 & $4.1-12.4$ & 8.9 & 4.3-19.4 & 38.1 & $38.1-38.1$ & 47.7 & 3-93.1 \\
\hline$V d_{s s^{\prime}} L$ & 77.7 & $51.1-134$ & 194 & $133-233$ & 783 & 783-783 & 255 & $8.4-1,530$ \\
\hline \multicolumn{9}{|l|}{ Sirolimus } \\
\hline $\mathrm{C}_{\max }, \mathrm{ng} / \mathrm{mL}$ & 52.4 & $29.6-66.4$ & 45.1 & $35.2-114$ & 104 & 69.4-152 & 247 & $106-451$ \\
\hline$t_{\max }, \mathrm{h}$ & 2.0 & $1.0-2.2$ & 6.0 & $1.0-25.3$ & 6.3 & $5.3-6.5$ & 2 & $1-5.5$ \\
\hline $\mathrm{t}, \mathrm{h}$ & 43.7 & $40.6-60.2$ & 43.9 & $38.1-49.7$ & 42.0 & $39.2-44.4$ & 36.6 & $31.6-58.4$ \\
\hline $\mathrm{A} \cup \mathrm{C}, \mathrm{h} \cdot \mathrm{ng} / \mathrm{mL}$ & 2,560 & $1,840-4,900$ & 4,520 & $3,050-5,990$ & 7,670 & $3,900-10,700$ & 8,660 & $7,220-15,900$ \\
\hline $\mathrm{CL} / f_{\mathrm{m}}, \mathrm{L} / \mathrm{h}$ & 3.9 & $3.4-6.6$ & 9.9 & $6.7-13.1$ & 14 & $10.6-17.5$ & 18.9 & $12-34$ \\
\hline$V d_{s s} / f_{m}, L$ & 290 & $198-432$ & 683 & $377-990$ & 665 & $146-924$ & 994 & $595-2,880$ \\
\hline$A \cup C_{\text {sum }}, \mathrm{ng} \mathrm{Eq} \cdot \mathrm{h} / \mathrm{mL}$ & 4,955 & $3,670-6,270$ & 10,218 & $5,120-15,315$ & 10,480 & $10,480-10,480$ & 14,898 & $12,031-19,492$ \\
\hline$A \cup C_{\text {ratio }}$ & 1.4 & $0.8-3.6$ & 1.1 & $0.6-1.5$ & 2.7 & $2.7-2.7$ & 2.7 & $1.2-4.4$ \\
\hline
\end{tabular}

points and the multicompartmental nature of the profiles. $\mathrm{C}_{\max }$ and AUC values did not differ significantly between courses 1 and 2 (data not shown). Median t ranged from 10.8 to 24.0 hours and tended to increase with increasing dose.

The sirolimus metabolite was rapidly formed, with a median $t_{\max }$ ranging from 2.0 to 6.3 hours. Sirolimus AUC and $\mathrm{AUC}_{\text {sum }}$ increased less than proportionally with dose. Exposure did not vary substantially between courses 1 and 2. The median $t$ ranged from 36.6 to 43.9 hours.

\section{Pharmacodynamics}

In total, 186 PBMC samples adequate for Western blot analysis were obtained from 17 patients. These included four patients treated with $10 \mathrm{mg} / \mathrm{m}^{2}$ of temsirolimus, four with $25 \mathrm{mg} / \mathrm{m}^{2}$, three with $75 \mathrm{mg} / \mathrm{m}^{2}$, and six with $150 \mathrm{mg} / \mathrm{m}^{2}$. Marked inter-patient variability was observed in PBMC content of phosphorylated (p) AKT, pS6, and $4 \mathrm{EBP} 1$ at all dose levels during course 1; however, reductions in all three phospho-proteins were detectable from 2 hours after temsirolimus dosing (Fig 1). Decreases in pAKT, pS6, and p4EBP1 were most notable at 168,8 , and 2 hours postdose, respectively, although numbers were too small to determine whether these represented true peaks in measured biologic response. An apparent late paradoxical increase in all three phospho-proteins was seen in the PBMC isolated from patients treated with $150 \mathrm{mg} / \mathrm{m}^{2}$, although this did not reach significance. Adequate material was available from course 2 PBMC for Western blotting of pAKT and p4EBP1 only. These data revealed a more profound and consistent inhibition of protein phosphorylation.

Despite the fact that $\mathrm{C}_{\max }$ and AUC increased with increasing dose administered, there was no evidence of a relationship between either the temsirolimus dose administered or the $\mathrm{C}_{\max }$ or AUC achieved and relative phosphorylation of AKT, p70S6, or 4EBP1. Similarly, there was no evidence that patients who experienced a complete tumor response or prolonged SD received higher temsiroli- mus doses, achieved higher $\mathrm{C}_{\max }$ or AUC values, or had lower relative phosphorylation of AKT, p70S6, or 4EBP1 than did the other patients.

\section{DISCUSSION}

This phase I study of intravenous temsirolimus demonstrated that the highest dose level tested, $150 \mathrm{mg} / \mathrm{m}^{2}$, was tolerable in pediatric patients with recurrent and refractory solid tumors. At this dose level, one patient experienced dose-limiting anorexia. Otherwise, toxicities were mild and grade 3 and 4 toxicities were virtually all hematologic. The most common nonhematologic toxicities were anorexia and hyperlipidemia. Drug-related pneumonitis, which has been observed in adult patients treated with temsirolimus, ${ }^{30}$ was not observed in this study. As expected from the mild toxicity profile, the median delivered doseintensity exceeded $95 \%$ for all dose levels tested. The toxicity of temsirolimus was similar to that observed in adult clinical trials and in a pediatric trial of another mTOR inhibitor, everolimus. ${ }^{19,29-34}$ Among the 13 patients evaluable for tumor response after six weekly doses of temsirolimus, one patient with neuroblastoma had a CR that was sustained for an additional 12 weeks and five patients had SD, three of whom remained on study for at least 4 months. These findings suggest that temsirolimus may have a role in the treatment of pediatric solid tumors, although further studies are needed to more precisely assess its spectrum and degree of activity.

We observed that temsirolimus $\mathrm{AUC}_{\text {sum }}$ in pediatric patients is comparable to respective values in adults for similar bracketed doses. ${ }^{19}$ The greater exposure to parent drug in pediatric patients was balanced by a shorter half-life of the sirolimus metabolite (median $t$ of 36.6 to 43.9 hours) and lower AUCs in pediatric patients compared with a t of 60.8 hours and commensurate higher sirolimus AUC in adult patients with solid tumors. Interestingly, the only patient in our study who 


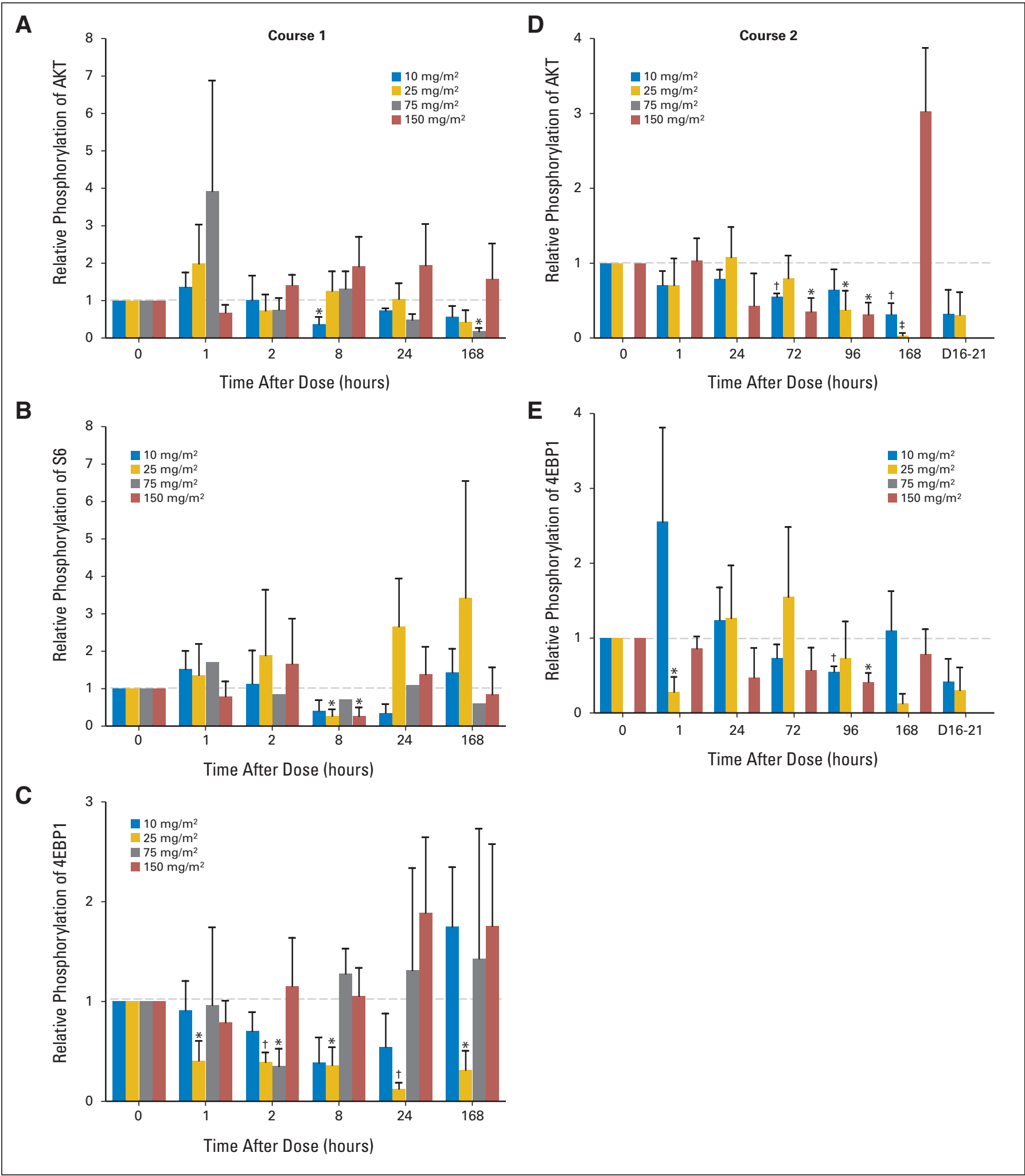

Fig 1. Relative phosphorylation of key signal proteins in the mammalian target of rapamycin pathway in peripheral-blood mononuclear cells of trial patients. Total level of each phosphorylated protein was normalized to the total level of the corresponding total protein by Western blot analysis. Each graph reports the level of normalized phosphorylated protein relative to time 0 postdose. Graphs report results for (A) Akt, (B) S6, and (C) 4EBP1 during course 1, and (D) AKT and (E) 4EBP1 during course 2. ${ }^{*} P<.05 . \dagger P<.005 . \ddagger P<.0005$ relative to time 0 . 
developed grade 4 thrombocytopenia had an unusually hightemsirolimus $\mathrm{C}_{\max }$ value; however, surrounding concentration measures for temsirolimus or sirolimus for this subject do not support a causal relationship. Previously, severity of thrombocytopenia was positively correlated with temsirolimus $\mathrm{C}_{\max }$ values in adults treated once-daily for 5 days every 2 weeks. ${ }^{33}$

In this study, we show that temsirolimus can significantly inhibit phosphorylation of AKT and 4EBP1 in PBMCs. Notably, inhibition was observed at doses as low as $10 \mathrm{mg} / \mathrm{m}^{2}$, and there did not appear to be a relationship between the temsirolimus dose administered and inhibition of AKT/4EBP1 phosphorylation, nor between temsirolimus serum levels achieved and inhibition of AKT/4EBP1 phosphorylation. These findings are consistent with those of a study in adults that documented mTOR downstream target inhibition after fixed doses as low as $25 \mathrm{mg}$ and found no relationship between the administered dose of temsirolimus and the degree of inhibition. ${ }^{18}$ In our study, pediatric patients who experienced a favorable tumor response (CR or prolonged SD) did not have lower relative phosphorylation of AKT, pS6, or 4EBP1 in their PBMCs. It is unclear whether this is because even mild inhibition of the mTOR pathway is sufficient in sensitive tumors to elicit a response or because the small number of patients included in this study prevented a clear association to be drawn between mTOR pathway inhibition in nonmalignant cells and tumor response. However, a lack of relationship between mTOR pathway protein inhibition and tumor response has also been documented in adult patients with glioblastoma multiforme. ${ }^{31}$ Further studies evaluating the relationship between administered dose and biologic effect are needed to confirm the preliminary findings in this study.

To summarize, temsirolimus seems to be a good candidate for further development in pediatric oncology as a result of its favorable safety profile and preclinical and clinical evidence of its activity in pediatric solid tumors. ${ }^{7,25,35,36}$ Dose selection for future trials is challenging because there is not a clear relationship between either dose administered or serum levels achieved and the degree of inhibition of mTOR downstream pathway proteins in surrogate tissues, nor is there a clear relationship between mTOR pathway inhibition and tumor response. Further studies are needed to clarify these issues. Preclinical data and findings from the phase I component of this study led to the phase II component evaluating temsirolimus in pediatric neuroblas- toma, ${ }^{36}$ rhabdomyosarcoma, ${ }^{7,25,37}$ and high-grade glioma, ${ }^{32,35}$ the results of which are presented separately. Future pediatric studies should explore combining temsirolimus with standard chemotherapy regimens ${ }^{14}$ and with other novel agents that target mTOR-related pathways, such as insulin-like growth factor-1 receptor antibodies and epidermal growth factor receptor inhibitors. ${ }^{21,38-41}$

\section{AUTHORS' DISCLOSURES OF POTENTIAL CONFLICTS OF INTEREST}

Although all authors completed the disclosure declaration, the following author(s) indicated a financial or other interest that is relevant to the subject matter under consideration in this article. Certain relationships marked with a " $U$ " are those for which no compensation was received; those relationships marked with a "C" were compensated. For a detailed description of the disclosure categories, or for more information about ASCO's conflict of interest policy, please refer to the Author Disclosure Declaration and the Disclosures of Potential Conflicts of Interest section in Information for Contributors.

Employment or Leadership Position: Jill Clancy, inVentiv Clinical Solutions (C); Anna Berkenblit, Wyeth/Pfizer (C); Mizue Krygowski, Wyeth/Pfizer (C); Joseph P. Boni, Wyeth/Pfizer (C) Consultant or Advisory Role: David J. Greenblatt, Pfizer (C); Revathi Ananthakrishnan, inVentiv Clinical Solutions (C) Stock Ownership: Anna Berkenblit, Pfizer; Mizue Krygowski, Pfizer; Joseph P. Boni, Pfizer Honoraria: None Research Funding: None Expert Testimony: None Other Remuneration: None

\section{AUTHOR CONTRIBUTIONS}

Conception and design: Sheri L. Spunt, Stephan A. Grupp, Terry A. Vik, Victor M. Santana, Joseph P. Boni, Richard J. Gilbertson

Provision of study materials or patients: Sheri L. Spunt,

Victor M. Santana

Collection and assembly of data: Sheri L. Spunt, Stephan A. Grupp,

Terry A. Vik, Anna Berkenblit, Richard J. Gilbertson

Data analysis and interpretation: Sheri L. Spunt, Stephan A. Grupp,

Terry A. Vik, David J. Greenblatt, Jill Clancy, Anna Berkenblit, Mizue Krygowski, Revathi Ananthakrishnan, Joseph P. Boni,

Richard J. Gilbertson

Manuscript writing: All authors

Final approval of manuscript: All authors

\section{REFERENCES}

1. Bjornsti MA, Houghton PJ: The TOR pathway: A target for cancer therapy. Nat Rev Cancer 4:335348, 2004

2. Dancey JE: Therapeutic targets: MTOR and related pathways. Cancer Biol Ther 5:1065-1073, 2006

3. Meric-Bernstam F, Gonzalez-Angulo AM: Targeting the mTOR signaling network for cancer therapy. J Clin Oncol 27:2278-2287, 2009

4. Aoki M, Blazek E, Vogt PK: A role of the kinase mTOR in cellular transformation induced by the oncoproteins P3k and Akt. Proc Natl Acad Sci U S A 98:136-141, 2001

5. Hara K, Yonezawa K, Kozlowski MT, et al: Regulation of elF-4E BP1 phosphorylation by mTOR. J Biol Chem 272:26457-26463, 1997

6. Sarbassov DD, Guertin DA, Ali SM, et al: Phosphorylation and regulation of Akt/PKB by the rictormTOR complex. Science 307:1098-1101, 2005
7. Dudkin L, Dilling MB, Cheshire PJ, et al: Biochemical correlates of mTOR inhibition by the rapamycin ester $\mathrm{CCl}-779$ and tumor growth inhibition. Clin Cancer Res 7:1758-1764, 2001

8. Podsypanina K, Lee RT, Politis C, et al: An inhibitor of $\mathrm{mTOR}$ reduces neoplasia and normalizes p70/S6 kinase activity in Pten+/- mice. Proc Natl Acad Sci U S A 98:10320-10325, 2001

9. Thomas GV, Tran C, Mellinghoff $I K$, et al: Hypoxia-inducible factor determines sensitivity to inhibitors of mTOR in kidney cancer. Nat Med 12:122127, 2006

10. $Y u$ K, Toral-Barza $L$, Discafani $C$, et al: MTOR, a novel target in breast cancer: The effect of $\mathrm{CCl}-779$, an mTOR inhibitor, in preclinical models of breast cancer. Endocr Relat Cancer 8:249258, 2001

11. Wu $C$, Wangpaichitr $M$, Feun $L$, et al: Overcoming cisplatin resistance by mTOR inhibitor in lung cancer. Mol Cancer 4:25, 2005

12. Asano $T$, Yao $Y$, Zhu J, et al: The rapamycin analog $\mathrm{CCl}-779$ is a potent inhibitor of pancreatic cancer cell proliferation. Biochem Biophys Res Commun 331:295-302, 2005

13. Wu L, Birle DC, Tannock IF: Effects of the mammalian target of rapamycin inhibitor CCl-779 used alone or with chemotherapy on human prostate cancer cells and xenografts. Cancer Res 65: 2825-2831, 2005

14. Teachey DT, Grupp SA, Brown VI: Mammalian target of rapamycin inhibitors and their potential role in therapy in leukaemia and other haematological malignancies. Br J Haematol 145: 569-580, 2009

15. Yazbeck VY, Buglio D, Georgakis GV, et al: Temsirolimus downregulates p21 without altering cyclin D1 expression and induces autophagy and synergizes with vorinostat in mantle cell lymphoma. Exp Hematol 36:443-450, 2008

16. Teachey DT, Obzut DA, Cooperman J, et al: The mTOR inhibitor $\mathrm{CCl}-779$ induces apoptosis and inhibits growth in preclinical models of primary adult human ALL. Blood 107:1149-1155, 2006 
17. Shi Y, Gera J, Hu L, et al: Enhanced sensitivity of multiple myeloma cells containing PTEN mutations to CCl-779. Cancer Res 62:5027-5034, 2002

18. Hudes G, Carducci M, Tomczak $P$, et al: Temsirolimus, interferon alfa, or both for advanced renal-cell carcinoma. N Engl J Med 356:2271-2281, 2007

19. Raymond $E$, Alexandre J, Faivre $S$, et al: Safety and pharmacokinetics of escalated doses of weekly intravenous infusion of $\mathrm{CCl}-779$, a nove mTOR inhibitor, in patients with cancer. J Clin Oncol 22:2336-2347, 2004

20. Peralba JM, DeGraffenried L, Friedrichs W, et al: Pharmacodynamic evaluation of $\mathrm{CCl}-779$, an inhibitor of mTOR, in cancer patients. Clin Cancer Res 9:2887-2892, 2003

21. Coulter DW, Blatt J, D'Ercole AJ, et al: IGF-I receptor inhibition combined with rapamycin or temsirolimus inhibits neuroblastoma cell growth. Anticancer Res 28:1509-1516, 2008

22. Dilling MB, Dias $P$, Shapiro DN, et al: Rapamycin selectively inhibits the growth of childhood rhabdomyosarcoma cells through inhibition of signaling via the type I insulin-like growth factor receptor. Cancer Res 54:903-907, 1994

23. Geoerger $B$, Kerr K, Tang CB, et al: Antitumor activity of the rapamycin analog $\mathrm{CCl}-779$ in human primitive neuroectodermal tumor/medulloblastoma models as single agent and in combination chemotherapy. Cancer Res 61:1527-1532, 2001

24. Hosoi H, Dilling MB, Liu LN, et al: Studies on the mechanism of resistance to rapamycin in human cancer cells. Mol Pharmacol 54:815-824, 1998

25. Wan X, Shen N, Mendoza A, et al: CCl-779 inhibits rhabdomyosarcoma xenograft growth by an antiangiogenic mechanism linked to the targeting of
mTOR/Hif-1alpha/NEGF signaling. Neoplasia 8:394401, 2006

26. Geoerger B, Kieran MW, Grupp S, et al: Phase 2 study of temsirolimus in children with high-grade glioma, neurosarcoma, and rhabdomyosarcoma. J Clin Oncol 28:688s, 2010 (suppl; abstr 9541)

27. Therasse P, Arbuck SG, Eisenhauer EA, et al: New guidelines to evaluate the response to treatment in solid tumors: European Organization for Research and Treatment of Cancer, National Cancer Institute of the United States, National Cancer Institute of Canada. J Natl Cancer Inst 92:205-216, 2000

28. Brodeur GM, Pritchard J, Berthold F, et al: Revisions of the international criteria for neuroblastoma diagnosis, staging, and response to treatment. J Clin Oncol 11:1466-1477, 1993

29. Fouladi M, Laningham F, Wu J, et al: Phase I study of everolimus in pediatric patients with refractory solid tumors. J Clin Oncol 25:4806-4812, 2007

30. Atkins MB, Hidalgo M, Stadler WM, et al: Randomized phase II study of multiple dose levels of CCl-779, a novel mammalian target of rapamycin kinase inhibitor, in patients with advanced refractory renal cell carcinoma. J Clin Oncol 22:909-918, 2004

31. Chan $S$, Scheulen ME, Johnston $S$, et al: Phase II study of temsirolimus (CCl-779), a novel inhibitor of mTOR, in heavily pretreated patients with locally advanced or metastatic breast cancer. J Clin Oncol 23:5314-5322, 2005

32. Galanis E, Buckner JC, Maurer MJ, et al: Phase II trial of temsirolimus (CCl-779) in recurrent glioblastoma multiforme: A North Central Cancer Treatment Group Study. J Clin Oncol 23:5294-5304, 2005

33. Hidalgo M, Buckner JC, Erlichman C, et al: A phase I and pharmacokinetic study of temsirolimus (CCl-779) administered intravenously daily for 5 days every 2 weeks to patients with advanced cancer. Clin Cancer Res 12:5755-5763, 2006

34. Witzig TE, Geyer SM, Ghobrial I, et al: Phase II trial of single-agent temsirolimus (CCl-779) for relapsed mantle cell Iymphoma. J Clin Oncol 23: 5347-5356, 2005

35. HuX, Pandolfi PP, Li Y, et al: MTOR promotes survival and astrocytic characteristics induced by Pten/AKT signaling in glioblastoma. Neoplasia 7:356368, 2005

36. Misawa A, Hosoi H, Tsuchiya K, et al: Rapamycin inhibits proliferation of human neuroblastoma cells without suppression of $\mathrm{MycN}$. Int J Cancer 104:233-237, 2003

37. Hosoi H, Dilling MB, Shikata T, et al: Rapamycin causes poorly reversible inhibition of MTOR and induces p53-independent apoptosis in human rhabdomyosarcoma cells. Cancer Res 59:886-894, 1999

38. Cao L, Yu Y, Darko I, et al: Addiction to elevated insulin-like growth factor I receptor and initial modulation of the AKT pathway define the responsiveness of rhabdomyosarcoma to the targeting antibody. Cancer Res 68:8039-8048, 2008

39. Doherty L, Gigas DC, Kesari S, et al: Pilot study of the combination of EGFR and mTOR inhibitors in recurrent malignant gliomas. Neurology 67: 156-158, 2006

40. Gallicchio $M A$, van Sinderen $M$, Bach $L A$ : Insulin-like growth factor binding protein- 6 and $\mathrm{CCl}$ 779, an ester analogue of rapamycin, additively inhibit rhabdomyosarcoma growth. Horm Metab Res 35:822-827, 2003

41. Kurmasheva RT, Dudkin L, Billups $C$, et al: The insulin-like growth factor-1 receptor-targeting antibody, CP-751,871, suppresses tumor-derived VEGF and synergizes with rapamycin in models of childhood sarcoma. Cancer Res 69:7662-7671, 2009 